\title{
Construindo o Conceito de Competência
}

\author{
Maria Tereza Leme Fleury \\ Afonso Fleury
}

\section{RESUMO}

Nos últimos anos, o tema competência, seu desenvolvimento, sua gestão, entrou para a pauta das discussões acadêmicas e empresariais, associado a diferentes instâncias de compreensão: no nível da pessoa (a competência do indivíduo), das organizações (as core competences) e dos países (sistemas educacionais e formação de competências). O objetivo deste trabalho é recuperar o debate teórico a respeito da noção de competência, explicitando o conceito em seus vários níveis de compreensão, relacionando-o à estratégia e aos processos de aprendizagem organizacional. Para tanto, o diálogo entre a literatura americana e a literatura européia, principalmente francesa, enriqueceu a construção deste conceito.

Palavras-chaves: competência; gestão de pessoas.

\begin{abstract}
The issue of competence building and management is currently gaining momentum at the academic and the managerial instances. The debates usually focus on one of three distinct levels of analysis: the level of the person (individual competences), the level of the enterprise (core competences of the organization) and the level of a region or nation (educational systems for the formation of local competences). The objective of this paper is to contribute to the theorethical discussion about competence building and management through the development of a conceptual framework, elaborated upon both the American and the European approaches. The key feature of that framework is the dynamic relationship between competitive strategy and competence management.
\end{abstract}

Key words: competence; human resources management. 


\section{APResentaçÃo}

Competência é uma palavra do senso comum, utilizada para designar uma pessoa qualificada para realizar alguma coisa. O seu oposto, ou o seu antônimo, não implica apenas a negação desta capacidade, mas guarda um sentimento pejorativo, depreciativo. Chega mesmo a sinalizar que a pessoa se encontra ou se encontrará brevemente marginalizada dos circuitos de trabalho e de reconhecimento social.

O dicionário Webster (1981, p. 63) define competência, na língua inglesa como: "qualidade ou estado de ser funcionalmente adequado ou ter suficiente conhecimento, julgamento, habilidades ou força para uma determinada tarefa". Esta definição, bastante genérica, menciona dois pontos principais ligados à competência: conhecimento e tarefa. O dicionário de língua portuguesa Aurélio enfatiza, em sua definição, aspectos semelhantes: capacidade para resolver qualquer assunto, aptidão, idoneidade e introduz outro: capacidade legal para julgar pleito.

Nos últimos anos, o tema competência entrou para a pauta das discussões acadêmicas e empresariais, associado a diferentes instâncias de compreensão: no nível da pessoa (a competência do indivíduo), das organizações (as core competences) e dos países (sistemas educacionais e formação de competências) ${ }^{(1)}$.

O objetivo deste texto é recuperar o debate teórico a respeito da noção de competência, estabelecendo o diálogo entre a literatura americana e européia. Buscando explicitar o conceito em seus vários níveis de compreensão, elaboramos um modelo, relacionando-o às estratégias organizacionais e aos processos de aprendizagem visando ao desenvolvimento de competências.

\section{O Início do Debate sobre Competência}

Em 1973, McClelland publicou o paper Testing for Competence rather than Intelligence, que de certa forma iniciou o debate sobre competência entre os psicólogos e os administradores nos Estados Unidos. A competência, segundo este autor, é uma característica subjacente a uma pessoa que é casualmente relacionada com desempenho superior na realização de uma tarefa ou em determinada situação. Diferenciava assim competência de aptidões: talento natural da pessoa, o qual pode vir a ser aprimorado, de habilidades, demonstração de um 
talento particular na prática e conhecimentos: o que as pessoas precisam saber para desempenhar uma tarefa (Mirabile, 1997).

Durante a década de 80, Richard Boyatzis, reanalisando os dados de estudos realizados sobre as competências gerenciais, identificou um conjunto de características e traços que, em sua opinião, definem um desempenho superior. Os trabalhos destes autores marcaram significativamente a literatura americana a respeito do tema competência (Spencer e Spencer, 1993; McLagan, 1996; Mirabile, 1997).

Nesta perspectiva, o conceito de competência é pensado como conjunto de conhecimentos, habilidades e atitudes (isto é, conjunto de capacidades humanas) que justificam um alto desempenho, acreditando-se que os melhores desempenhos estão fundamentados na inteligência e personalidade das pessoas. Em outras palavras, a competência é percebida como estoque de recursos, que o indivíduo detém. Embora o foco de análise seja o indivíduo, a maioria dos autores americanos sinalizam a importância de se alinharem as competências às necessidades estabelecidas pelos cargos, ou posições existentes nas organizações.

Ou seja, tanto na literatura acadêmica, como nos textos que fundamentam a prática administrativa, a referência que baliza o conceito de competência é a tarefa e o conjunto de tarefas pertinentes a um cargo. Nesta linha, a gestão por competência é apenas um rótulo mais moderno para administrar uma realidade organizacional ainda fundada nos princípios do taylorismo-fordismo.

Lawler argumenta contra esta linha de raciocínio, mostrando que trabalhar com o conjunto de habilidades e requisitos definidos a partir do desenho do cargo, próprios do modelo taylorista, não atende às demandas de um organização complexa, mutável em um mundo globalizado. Em tais situações, afirma este autor, as organizações deverão competir não mais apenas mediante produtos, mas por meio de competências, buscando atrair e desenvolver pessoas com combinações de capacidades complexas, para atender às suas core competences. As observações deste autor merecem ser registradas, porquanto, alinhadas com as observações de autores europeus, propiciarão a fundamentação para a elaboração de nosso modelo de análise.

Observa-se assim que, enquanto prevaleceu o modelo taylorista e fordista de organização do trabalho e de definição das estratégias empresariais, o conceito de qualificação propiciava o referencial necessário para se trabalhar a relação profissional indivíduo-organização. A qualificação é usualmente definida pelos requisitos associados à posição, ou ao cargo, ou pelos saberes ou estoque de conhecimentos da pessoa, os quais podem ser classificados e certificados pelo sistema educacional. 
O debate francês a respeito de competência nasceu nos anos 70, justamente do questionamento do conceito de qualificação e do processo de formação profissional, principalmente técnica. Insatisfeitos com o descompasso que se observava entre as necessidades do mundo do trabalho (principalmente da indústria), procuravam aproximar o ensino das necessidades reais das empresas, visando a aumentar a capacitação dos trabalhadores e suas chances de se empregarem. Buscava-se estabelecer a relação entre competências e os saberes - o saber agir no referencial do diploma e do emprego. Do campo educacional o conceito de competência passou a outras áreas, como o campo das relações trabalhistas, para se avaliarem as qualificações necessárias ao posto de trabalho, nascendo assim o inventário de competências: bilan de compétences.

O conceito de competência, que emerge na literatura francesa dos anos 90 , procurava ir além do conceito de qualificação. Zarifian (1999) foca três mutações principais no mundo do trabalho, que justificam a emergência do modelo de competência para a gestão das organizações:

. A noção de incidente, aquilo que ocorre de forma imprevista, não programada, vindo a perturbar o desenrolar normal do sistema de produção, ultrapassando a capacidade rotineira de assegurar sua auto-regulação; isto implica que a competência não pode estar contida nas pré-definições da tarefa; a pessoa precisa estar sempre mobilizando recursos para resolver as novas situações de trabalho.

- Comunicação: comunicar implica compreender o outro e a si mesmo; significa entrar em acordo sobre objetivos organizacionais, partilhar normas comuns para a sua gestão.

- Serviço: a noção de serviço, de atender a um cliente externo ou interno da organização precisa ser central e estar presente em todas as atividades; para tanto, a comunicação é fundamental.

O trabalho não é mais o conjunto de tarefas associadas descritivamente ao cargo, mas se torna o prolongamento direto da competência que o indivíduo mobiliza em face de uma situação profissional cada vez mais mutável e complexa. Esta complexidade de situações torna o imprevisto cada vez mais cotidiano e rotineiro.

No caso brasileiro, este debate emerge na discussão acadêmica fundamentado inicialmente na literatura americana, pensando-se competência como input, algo que o indivíduo tem. A introdução de autores franceses como Le Boterf, Zarifian, autores ingleses como Jacques e seus seguidores (Billis e Rowbottom, Stamp e Stamp), contribuem para o enriquecimento conceitual e empírico, gerando novas 
perspectivas e enfoques (Rhinow, 1998; Amatucci, 2000; Fleury e Fleury, 2000; Hipolito, 2000; Rodrigues, 2000; Ruas, 2000).

\section{Construindo o Conceito de Competência do Indivíduo}

Na perspectiva adotada neste trabalho, a competência não se limita a um estoque de conhecimentos teóricos e empíricos detido pelo indivíduo, nem se encontra encapsulada na tarefa. Segundo Zarifian (1999) a competência é a inteligência prática para situações que se apóiam sobre os conhecimentos adquiridos e os transformam com tanto mais força, quanto mais aumenta a complexidade das situações.

A competência do indivíduo não é um estado, não se reduz a um conhecimento ou know how específico. Le Boterf(1995) situa a competência numa encruzilhada, com três eixos formados pela pessoa (sua biografia, socialização), pela sua formação educacional e pela sua experiência profissional. A competência é o conjunto de aprendizagens sociais e comunicacionais nutridas a montante pela aprendizagem e formação e a jusante pelo sistema de avaliações. Segundo ainda este autor: competência é um saber agir responsável e que é reconhecido pelos outros. Implica saber como mobilizar, integrar e transferir os conhecimentos, recursos e habilidades, num contexto profissional determinado.

A competência individual encontra seus limites, mas não sua negação no nível dos saberes alcançados pela sociedade, ou pela profissão do indivíduo, numa época determinada. As competências são sempre contextualizadas. Os conhecimentos e o know how não adquirem status de competência a não ser que sejam comunicados e utilizados. A rede de conhecimento em que se insere o indivíduo é fundamental para que a comunicação seja eficiente e gere a competência.

A noção de competência aparece assim associada a verbos como: saber agir, mobilizar recursos, integrar saberes múltiplos e complexos, saber aprender, saber engajar-se, assumir responsabilidades, ter visão estratégica. Do lado da organização, as competências devem agregar valor econômico para a organização e valor social para o indivíduo. 


\section{Figura 1: Competências como Fonte de Valor para o Indivíduo e para a Organização}

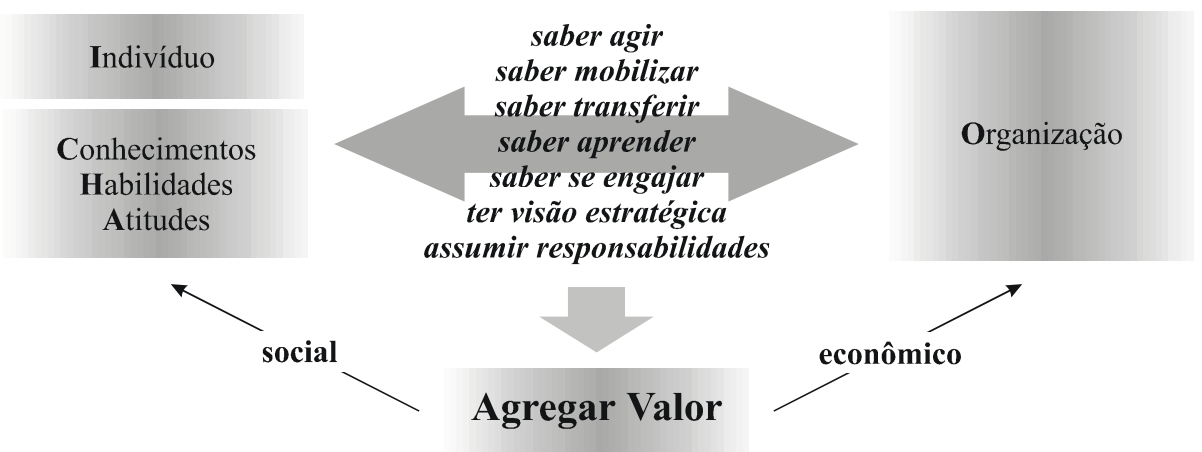

Definimos assim competência: um saber agir responsável e reconhecido, que implica mobilizar, integrar, transferir conhecimentos, recursos e habilidades, que agreguem valor econômico à organização e valor social ao indivíduo.

O que significam os verbos expressos neste conceito? O quadro a seguir (inspirado na obra de Le Boterf) propõe algumas definições.

\section{Quadro 1: Competências para o Profissional}

\begin{tabular}{|c|c|}
\hline Saber agir & $\begin{array}{l}\text { Saber o que e por que faz } \\
\text { Saber julgar, escolher, decidir. }\end{array}$ \\
\hline $\begin{array}{l}\text { Saber mobilizar } \\
\text { recursos }\end{array}$ & Criar sinergia e mobilizar recursos e competências. \\
\hline Saber comunicar & $\begin{array}{l}\text { Compreender, trabalhar, transmitir informações, } \\
\text { conhecimentos. }\end{array}$ \\
\hline Saber aprender & $\begin{array}{l}\text { Trabalhar o conhecimento e a experiência, rever } \\
\text { modelos mentais; saber desenvolver-se. }\end{array}$ \\
\hline $\begin{array}{l}\text { Saber engajar-se e } \\
\text { comprometer-se }\end{array}$ & $\begin{array}{l}\text { Saber empreender, assumir riscos. } \\
\text { Comprometer-se. }\end{array}$ \\
\hline $\begin{array}{l}\text { Saber as sumir } \\
\text { responsabilidades }\end{array}$ & $\begin{array}{c}\text { Ser responsável, assumindo os riscos e } \\
\text { conseqüências de suas ações e sendo por isso } \\
\text { reconhecido. }\end{array}$ \\
\hline Ter visão es tratégica & $\begin{array}{c}\text { Conhecer e entender o negócio da organização, o } \\
\text { seu ambiente, identificando oportunidades e } \\
\text { alternativas. }\end{array}$ \\
\hline
\end{tabular}




\section{As Competéncas de uma Organização: o Linkentre Estratégia e CompetencaA}

Rebatendo a discussão das competências do indivíduo para as competências das organizações, introduz-se a noção da empresa como carteira de competências.

Durand (1998) assevera que "nos tempos medievais, os alquimistas procuravam transformar metais em ouro; os gerentes e as empresas hoje procuram transformar recursos e ativos em lucro. Uma nova forma de alquimia é necessária às organizações. Vamos chamá-la de "competência"”.

Os artigos de Prahalad e Hamel (1990) sobre as core competences da empresa despertaram o interesse não só de pesquisadores, mas também entre os profissionais de empresas, para as teorias sobre recursos da firma (resource based view of the firm). Segundo esses autores, para ser chave as competências deveriam responder a três critérios: oferecer reais benefícios aos consumidores, ser difícil de imitar e prover acesso a diferentes mercados. A questão principal diz respeito à possibilidade de combinação das várias competências que uma empresa pode conseguir para desenhar, produzir e distribuir produtos e serviços aos clientes no mercado. Competência seria assim a capacidade de combinar, misturar e integrar recursos em produtos e serviços.

Uma competência essencial não precisa necessariamente ser baseada em tecnologia stricto sensu: ela pode estar associada ao domínio de qualquer estágio do ciclo de negócios, como por exemplo um profundo conhecimento das condições de operação de mercados específicos. Não obstante, para ser considerado uma competência essencial, esse conhecimento deve estar associado a um sistemático processo de aprendizagem, que envolve descobrimento/inovação e capacitação de recursos humanos.

Zarifian (1999) diferencia as seguintes competências em uma organização.

- Competências sobre processos: os conhecimentos do processo de trabalho.

- Competências técnicas: conhecimentos específicos sobre o trabalho que deve ser realizado.

. Competências sobre a organização: saber organizar os fluxos de trabalho.

- Competências de serviço: aliar à competência técnica a pergunta: qual o impacto que este produto ou serviço terá sobre o consumidor final?

- Competências sociais: saber ser, incluindo atitudes que sustentam os comportamentos das pessoas; o autor identifica três domínios destas competências: autonomia, responsabilização e comunicação. 
Esta classificação proposta por Zarifian (1999) ilumina a formação de competências mais diretamente ligadas ao processo de trabalho de operações industriais. A nosso ver é preciso ampliar o escopo de análise, relacionando a formação de competências à definição da estratégia organizacional. $\mathrm{O}$ esquema a seguir ilustra o raciocínio desenvolvido neste trabalho:

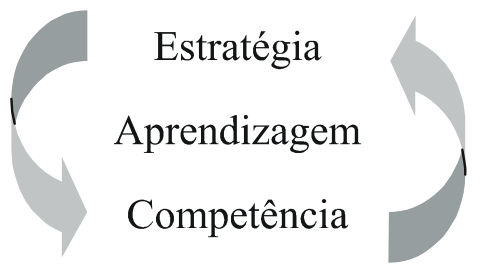

Segundo esta abordagem, a organização, situada em uma ambiente institucional, define a sua estratégia e as competências necessárias para implementá-las, num processo de aprendizagem permanente. Não existe uma ordem de precedência neste processo, mas antes um círculo virtuoso, em que uma alimenta a outra mediante o processo de aprendizagem.

\section{Competências e Aprendizagem}

Como desenvolver as competências em uma organização? Para responder a esta questão é necessário percorrer o caminho que vai da aprendizagem individual, para a aprendizagem em grupo, para aprendizagem na organização.

Iniciando com o indivíduo, a questão que se coloca é: como eu aprendo?

Esta questão aparentemente simples implica uma viagem interior, que recupera momentos em que o conhecimento se mistura com a emoção, sinalizando situações positivas e situações tensas e angustiantes.

A aprendizagem é um processo neural complexo, que leva à construção de memórias. Aquilo que se aprende e depois se esquece é como se nunca tivesse acontecido; o conjunto de coisas de que nos lembramos constitui a nossa identidade. Como o coloca Izaquierdo (1997), o indivíduo é exatamente só aquilo de que se lembra; eu sou quem sou porque me lembro de quem sou, porque sei quem sou. Se não nos lembrássemos de nada, não seríamos alguém; por isso é tão trágica a fase final da doença de Alzheimer, ou a ignorância do próprio eu. 
Aprendo lendo, aprendo ouvindo, aprendo errando, aprendo na prática, aprendo vivenciando a situação na minha cabeça, aprendo observando os outros. Inúmeras são as formas de aprender e cada pessoa se vê única nesse processo.

Cada espécie animal utiliza mais determinado tipo de percepção para aprender; o ser humano é predominantemente visual e verbal, utilizando aquilo que Pavlov (apud Izaquierdo, 1997) denominou o verbal ou simbólico, de preferência aos demais. A memória visual humana é maior que a auditiva, e a memória verbalvisual é maior que a oral. A quantidade de informações que pode ser adquirida na aprendizagem verbal-visual é maior do que a que pode ser retida pela comunicação oral. Um exemplo são as línguas transmitidas oralmente e que desaparecem, enquanto as línguas transmitidas pela escrita e leitura sobrevivem.

As emoções e os afetos regulam o aprendizado e a formação de memórias. As pessoas se lembram melhor daquilo que lhes despertou sentimentos positivos do que daquilo que thes despertou sentimentos negativos e se lembram mal daquilo que as deixou indiferentes. As emoções contribuem fortemente na motivação para a pessoa aprender; parecem dar cor e sabor ao que aprende.

Aprendizagem pode ser assim pensada como um processo de mudança, provocado por estímulos diversos, mediado por emoções, que pode vir ou não a manifestar-se em mudança no comportamento da pessoa.

Os psicólogos enfatizam a necessidade de distinguir entre o processo de aprendizagem, que ocorre dentro do organismo da pessoa que aprende, e as respostas emitidas por esta pessoa, as quais podem ser observáveis e mensuráveis. Duas vertentes teóricas sustentam os principais modelos de aprendizagem: o modelo behaviorista e o modelo cognitivista.

- Modelo behaviorista: seu foco principal é o comportamento, pois este é observável e mensurável; partindo do princípio de que a análise do comportamento significa o estudo das relações entre eventos estimuladores e as respostas, planejar o processo de aprendizagem implica estruturar este processo em termos passíveis de observação, mensuração e réplica científica.

Modelo cognitivo: pretende ser um modelo mais abrangente do que o behaviorista, explicando melhor os fenômenos mais complexos, como a aprendizagem de conceitos e a solução de problemas; procura utilizar tanto dados objetivos e comportamentais, como dados subjetivos, levando em consideração as crenças e percepções do indivíduo que influenciam seu processo de apreensão da realidade.

A teoria da Gestalt, precursora do cognitivismo, pesquisa o processo de aprendizagem por insights. "O indivíduo que tem um insight vê uma situação de uma 
nova maneira, que implica a compreensão das relações lógicas ou percepção das conexões entre meios e fins" (Hill, 1981).

As discussões sobre aprendizagem dos indivíduos em organizações se enraízam mais fortemente na perspectiva cognitivista, enfatizando porém as mudanças comportamentais observáveis. Como as pessoas aprendem e desenvolvem as competências necessárias à organização e ao seu projeto profissional?

Le Boterf (1995) propõe o seguinte quadro sobre o processo de desenvolvimento de competências das pessoas nas organizações:

\begin{tabular}{|c|c|c|}
\hline Tipo & Função & Como Des envolver \\
\hline $\begin{array}{c}\text { Conhecimento } \\
\text { teórico. }\end{array}$ & $\begin{array}{c}\text { Entendimento, } \\
\text { interpretação. }\end{array}$ & $\begin{array}{c}\text { Educação formal e } \\
\text { continuada. }\end{array}$ \\
\hline $\begin{array}{c}\text { Conhecimento sobre } \\
\text { os procedimentos. }\end{array}$ & Saber como proceder. & $\begin{array}{c}\text { Educação formal e } \\
\text { experiência profissional }\end{array}$ \\
\hline $\begin{array}{c}\text { Conhecimento } \\
\text { empírico. }\end{array}$ & Saber como fazer. & Experiência profissional \\
\hline $\begin{array}{c}\text { Conhecimento social. } \\
\text { Conhecimento } \\
\text { cognitivo. }\end{array}$ & $\begin{array}{c}\text { Saber como comportar-se. } \\
\text { informação, saber como a } \\
\text { aprender. }\end{array}$ & $\begin{array}{c}\text { Experiência social e } \\
\text { profissional }\end{array}$ \\
\hline
\end{tabular}

Observa-se assim a conjugação de situações de aprendizagem que podem propiciar a transformação do conhecimento em competência. Esta transformação, como já mencionamos no item anterior, só acontece em contexto profissional específico, pois a realização da competência deverá não apenas agregar valor ao indivíduo, mas também à organização.

A questão, porém, que tem mais preocupado tanto os teóricos como os profissionais ou practitioners da aprendizagem diz respeito a como passar da aprendizagem individual para a organizacional. Sem querer antropomorfizar o conceito de aprendizagem organizacional, é possível distinguir entre os vários níveis em que este processo pode ocorrer, como nos três seguintes.

- Nível do indivíduo: o processo de aprendizagem ocorre primeiro no nível do indivíduo, carregado de emoções positivas ou negativas, através de caminhos diversos.

- Nível do grupo: a aprendizagem pode ocorrer em um processo social e coletivo; para compreendê-lo é preciso observar como o grupo aprende, como combina os conhecimentos e as crenças individuais, interpretando-as e integrando-as 
em esquemas coletivos partilhados; estes, por sua vez, podem constituir orientações para ações; o desejo de pertencer ao grupo pode constituir um elemento motivacional no processo de aprendizagem.

. Nível da organização: o processo de aprendizagem individual, de compreensão e interpretação partilhadas pelo grupo se torna institucionalizado e expresso em diversos artefatos organizacionais: na estrutura, no conjunto de regras e procedimentos e elementos simbólicos; as organizações desenvolvem memórias que retêm e recuperam informações.

As organizações podem não ter cérebros, mas têm sistemas cognitivos e memórias; desenvolvem rotinas, procedimentos relativamente padronizados para lidar com os problemas internos e externos. Estas rotinas vão sendo incorporadas, de forma explícita ou inconsciente, na memória organizacional. A mudança em processos, estruturas ou comportamentos não seria o único indicador de que a aprendizagem aconteceu, mas a possibilidade deste conhecimento ser recuperado pelos membros da organização.

Além disso, o processo de aprendizagem em uma organização envolve não só a elaboração de novos mapas cognitivos, que possibilitem compreender o que está ocorrendo no ambiente externo e interno da organização, como também a definição de novos comportamentos que comprovam a efetividade do aprendizado.

As definições mais comuns de uma organização que aprende enfatizam a sua capacidade de adaptação às taxas aceleradas de mudança que ocorrem atualmente no mundo. Entretanto, como o assinala Senge (1990), a adaptabilidade crescente constitui apenas o primeiro passo no processo de aprendizagem. $\mathrm{O}$ desejo de aprender vai mais adiante: é criativo e produtivo.

Lyles (1999) diferencia dois níveis de aprendizagem: o nível mais baixo, ou o chamado de conhecimento explícito, resultante de repetições e rotinas; é o conhecimento que pode ser explicado e codificado. O conhecimento de nível mais alto envolve o ajustamento de crenças e normas, o que resulta em novos quadros de referência, novas habilidades, chegando mesmo um momento de desaprender coisas que fizeram sucesso no passado e que hoje não têm mais razão de ser. É o conhecimento tácito, às vezes inconsciente, que se apóia na memória organizacional. Observa-se nesta perspectiva o aliar-se da vertente mais cognitivista sobre a aprendizagem à abordagem cultural.

Em suma, é por meio dos processos de aprendizagem que a organização desenvolve as competências essenciais à realização de suas estratégias de negócio. 


\section{Comentários Finals}

O objetivo deste artigo foi contribuir para a compreensão do conceito de competência - um conceito em construção - nas palavras de Le Boterf (1995), em duas instâncias de análise: do indivíduo e da organização.

Trabalhar o conceito de competência associado à estratégia e à aprendizagem organizacional, com todo o seu potencial heurístico, implicou uma viagem pelo Atlântico, procurando o diálogo entre a literatura americana e européia. A tropicalização do conceito, por nós realizada, foi fruto não apenas de uma reflexão teórica, mas resultado de trabalhos de pesquisa e consultoria (Fleury e Fleury, 2000).

A noção de competência, explorada neste texto, lança luz sobre um aspecto importante: se por um lado, agrega valor econômico à organização, por outro não menos relevante deve agregar valor social ao indivíduo, ou seja, as pessoas, ao desenvolverem competências essenciais para o sucesso da organização, estão também investindo em si mesmas, não só como cidadãos organizacionais, mas como cidadãos do próprio país e do mundo.

\section{Nota}

${ }^{1}$ No livro Estratégias Empresariais e Formação de Competências (Fleury e Fleury, 2000), as várias
instâncias da discussão do conceito de competência são incorporadas, trabalhando-se, por exemplo,
os vários arranjos empresariais e a formação de competências em redes, cadeias e clusters de empresas.

\section{REFERÊNCIAS BibLIOGRÁFICAS}

\section{AMATUCCI, $\mathrm{M}$.}

\section{Perfil do administrador brasi- leiro para o século XXI: um en- foque metodológico. São Paulo, 2000. Dissertação (Mestrado) - Faculdade de Economia, Admi- nistração e Contabilidade, Uni- versidade de São Paulo.}

DURAND.

Forms of incompetence. Trabalho apresentado na 'Conference of Management of Competence', Oslo, 1998. 
FLEURY, A. C. C.;

FLEURY, M. T. L.

Estratégias empresariais e formação de competências.

São Paulo: Atlas, 2000.

HILL, W.

Aprendizagem. Rio de Janeiro: Guanabara, 1981.

HIPÓLITO, J. A. M.

\section{A gestão da administração} salarial em ambientes competitivos: análise de uma metodologia para construção de sistemas de remuneração por competências. São Paulo, 2000. Dissertação (Mestrado) - Faculdade de Economia, Administração e Contabilidade, Universidade de São Paulo.

\section{IZAQUIERDO, I.}

Inteligência e aprendizagem no mercado de trabalho. In: CASALI, A. et al. (Orgs.). Empregabilidade e organização. São Paulo: Educ Rhodia, 1997.

\section{LE BOTERF, G.}

De la compétence - essai sur un attracteur étrange. In: Les éditions d'organisations. Paris: Quatrième Tirage, 1995.

LYLES, M. A.

Organizational learning and knowledge transfer in international joint ventures.

Trabalho apresentado no Seminário Internacional Competitividade Organizacional Gestão do Conhecimento e Universidade Corporativa, São Paulo, 1999.

MCCLELLAND, D. C.;

SPENCER, L. M.

Competency assessment methods: history and state of the art. Hay McBer Research Press, 1990.

PORTER, M. E.

What's strategy? Harvard Business Review, v. 74, n. 6, Nov./Dec. 1996.

PRAHALAD, C. K.;

HAMEL, G.

The core competence of the corporation. Harvard Business Review, v. 68, n. 3, May/June 1990.

RHINOW, G.

Dinâmica de aprendizagem voltada para a competitividade: estudo de caso em uma empresa transnacional de bens de consumo. São Paulo, 1998. Dissertação (Mestrado) - Faculdade de Economia, Administração e Contabilidade, Universidade de São Paulo. 
RODRIGUES, S. B.

From factories to shops: deconstruction of scientific knowlegde without a client. In: Gestão estratégica do conhecimento: integrando aprendizagem, conhecimento e competências. São Paulo: Atlas, 2000.

\section{RUAS, R.}

A problemática do desenvolvimento de competências e a contribuição da aprendizagem organizacional. In: Gestão estratégica do conhecimento: integrando aprendizagem, conhecimento e competências. São Paulo: Atlas, 2000.
SENGE, P.

The fifth discipline: the art and practice of the learning organization. New York : DoubleDay/Currency, 1990.

SPENCER, L. M.;

SPENCER, S. M.

Competence at work: models for superior performance. New York: John Wiley \& Sons, 1993.

WEBSTER.

Webster's third new international dictionary of the english language, unabridged. Springfield: G. \& C. Merriam, 1981.

ZARIFIAN, P.

Objectif compétence. Paris: Liaisons, 1999. 